\title{
Research on Quality Structure of College Journal Editors
}

\author{
Wang Fang \\ Chinese People's Armed Police Forces and Officers College, Chengdu, Sichuan, China
}

fangwangsichuan@163.com

Keywords: Quality structure; Editors; Higher vocational colleges

\begin{abstract}
College journal editors' quality has a direct impact on the quality of the college journal. In this paper, we firstly give the concept of quality and quality structure, and then point out that the essential quality structure of college journal editors which includes political quality, academic quality, professional quality, psychological quality and service quality in order to provide reference for relevant researchers.
\end{abstract}

\section{Introduction}

The college journal is an important part of science and technology journals in China, but it is different from other general journals. College journal is sponsored by universities or colleges in order to reflect the university's teaching and scientific research achievements. The theory of operation of publications is an important field to carry out academic exchanges at home and abroad. Therefore, college journal is shouldering the important task of socialist material civilization and spiritual civilization, but also to better promote the quality of talent training, discipline construction, building characteristics to enhance scientific and technological development level and expand the influence of academic exchange and so on. Thus the editors of university journals not only do some word processing format specification, the basic processing work desk, quality to be able to edit and should have multiple dimensions so that the journal play their functions. In the new era of science and technology, universities must be prepared. In the new century, the college journal must get rid of the traditional mechanism, publishing and international journals to create value of colleges and universities in the new journal of colleges and universities to build international brands. Especially the young editors of college journals as an independent social occupation have to face the severe challenges to build the solid quality structure.

\section{Concept of Quality Structure}

Quality is individual characteristics which are measured in the specific work, organization environment and the cultural atmosphere. The quality factor of a person, such as the values, attitudes, self-image, social role, personality and motivation is relatively stable; knowledge, skills in a certain period of time are relatively stable. Trend of degeneration is over time, age, stage, the level and the change of the environment, the editor's knowledge and skills may be added, values, attitudes, self-image, social role, personality and motivation will change. The quality structure is the constituent elements of quality and the way they interact with each other. The qualities are interrelated and interacting with each other, and in a certain form in one person, decide a person's development, the development level of the possibility of not one or several quality, but the quality of the whole structure. Some scholars in the educational function of objective function are divided into the quality of mind and body, etc. the five elements. The common quality factors include the natural quality and social quality, physiological quality, psychological quality, psychological quality, personality, psychological quality, psychological quality, cultural quality and cultural foundation, the knowledge quality, ability quality, scientific quality and humanistic quality, political quality, ideological quality and moral quality, aesthetic quality and labor quality, personality the practice of quality and professional quality, etc.

Quality Structure of Editors in Higher Vocational Colleges 
A: Political Quality. Political quality refers to the quality of editors grasp the political stand, political views and political orientation, including the ability and level of national, political, ethnic and religious issues, which is the core element of journal editors' quality. Orientation error of journals of colleges and universities cannot appear orientation error. The editors should in thought, politics and action consciously highly consistent with the Party Central Committee and resolutely implement the provisions of the state on science and technology and publishing the relevant security, copyright, patent, borders, strictly abide by the guidelines, policies and regulations related to the party and the State Press and publication, in the nation, religion, law, military and diplomatic and other major political issues of principle and sensitive issues should always adhere to prudent attitude. Editing work is characteristic of ideology, politics, economy, culture, science and technology are reflected. It is not possible to want to detach the politics. As a qualified editor, must establish a strong political consciousness, overall situation consciousness, responsibility consciousness, editorial work is pure business and political point of view, there is no need to resolutely put an end. College journal editors' political and moral culture is the guarantee to the implementation of the principle.

B: Academic Quality. Academic quality includes the quality of the editorial staff to control the essays published in the academic quality and academic level of competence. It also includes the quality of editors in editing and publishing of academic attainments. This is the premise of survival and development in the fierce competition in the market, but also the key elements of the editors of journals quality. The journal must reflect the change and development of modern economic and social propaganda, combined with changes in the current situation, follow closely and reflect the natural, social and academic circles, theory circles focus, focus and difficult issues, to give the reader a useful academic education and Enlightenment of the. Journal editors should have solid professional knowledge. This is the premise for the journal. The editor should be involved in the contents of the editing process are widely understood. Journal Editors professional knowledge on the subject of the familiar, determines its grasp of the edited content. Journal editors may not be general each subject can be well versed in. They can stand a certain height in a certain area, within a certain range. To grasp the overall development trend of this field, understand the new knowledge. Journal Editors' professional knowledge the academic ability to identify high to edit a manuscript, able to quickly distinguish between good and bad discard the dross and select the essential in editing and manuscript in the process of trial. The college editors in the editorial department should determine the different division of labor according to each editor's different professional knowledge in order to better grasp the different disciplines of manuscript.

C: Professional Quality. Professional quality refers to the ability of the manuscript review editors soliciting contributions, editing staff assessment level, ability to ensure the academic quality, level of processing and planning journal column, processing the format specification and text symbols of editors and peer reviewers. Therefore, editing quality is the key to improve quality of journals, to try to do well in the continuity of programs, content and style. The editorial quality to meet the academic standard, columns have characteristics, and match the reasonable use of language must be standardized, concise, correct concept to no knowledge of error, the title, the directory to the error free, units of measurement, formula, punctuation, writing format to meet the requirements of standard specifications. College journal editors in editing object mostly is the latest research results in this field, open or create the new frontiers of scientific research, it is the latest research results of the most direct propaganda, outside the window, is the bridge of directly facing the market, in circulation in the market. Journal editors must be on the field theory, research methods and the problems need to be solved and the trend of development has a deep grasp of the system, so that cannot unfamiliar to edit the object in order to improve the quality of editing, editing quality guarantee. Cultural and scientific knowledge and knowledge framework, natural science and social science mutual penetration and integration, rich and solid knowledge system is an important foundation for the modern people's quality structure. At the same time of the college journal editor maximum his limited knowledge, he also have to build a best knowledge structure optimization to be a comprehensive editor. 
D: Psychological Quality. Editors must have a stable and lasting attention and thinking ability. The general performance of attention quality of college journal editors includes the editing, distribution, transfer to the breadth, concentration and stability and other aspects of attention. College journal editors must possess good attention quality, to have a comprehensive and clear perception of the manuscript many information, can also deal with the text, data, charts, formulas and the relationship between the information in the manuscript. If the attention span is not enough, it is easy to loss in the work. If the attention allocation is unreasonable, or the transfer of attention is not timely, often pay attention to words and ignore the chart, which should not appear in the error. If the attention is not centralized, instability cannot be careful, meditation about manuscript processing problems in the emergence of proofreading. Closed thinking characteristic of editing must have good interpersonal skills and ability to withstand setbacks. On the one hand, the editor should be a good man to get along with people. Characteristics of the editor's decision to the characteristics of their work is to build bridges with authors and readers, editors should know the author, but also to understand the psychological characteristics of the audience, to the author and the reader, to study the culture of different groups of people. Therefore, the editor must be good at with all types of people, to communicate with the author to make the article more valuable; communicate with the reader understand what they need in order to solicit articles; extensive contact with the experts and scholars to understand the advanced development of the subject, to capture valuable information of science and technology; editing and peer exchanges, to improve the level of business and the quality of the journal. These have to be good at getting along with people, communication and coordination, the establishment of good interpersonal relationships, in order to keep the communication channels open. On the other hand, the editor should be one that can withstand frustrations. The fierce competition, the tedium of the work, "the wedding dress for others, the knowledge structure and the reserves cannot keep up with the rapid development of the social pressure, because the competition may lead to tension in the relationship and so on to bring psychological anxiety, tension and even edit frustration. Therefore, the ability to withstand setbacks is college journal editors' necessary quality.

E: Service Quality. Service quality refers to the quality and ability of editorial staff service to authors, readers, and effective coordination and interaction. Editorial staff in Editorial Department and all the committee members, including the authors, reviewers, temporary special editors, proofreaders, external input typesetting, printing and binding for all involved personnel of editing and publishing work, all participants, service. Therefore, these people are going to have a good attitude and team spirit, and good management relations and management, service and service, to build a harmonious environment in order to editing and publishing. On the other hand, the journal also should serve the academic exchanges, serving for discipline construction and personnel training, serve the teaching and scientific research work, development characteristic and the advantage and integration, and promote each other so as to improve the quality of the college journal.

\section{Conclusion}

As a comprehensive academic journal, the college journal has the characteristics of science, knowledge and academic. The college journal is the link of teaching and scientific research and the bridge between, display university teaching level and scientific research ability, through continuous absorption and transmission of new achievements in scientific research to promote the development and innovation of university teaching and scientific research work, expand the influence. At the same time is also an important window of the foreign exchange, universities and social scientific research achievement is a significant part of this spread through the carrier, to promote academic exchanges. College journal is a comprehensive academic journal of colleges and universities teaching scientific research results show, the quality of university journal editor, social impact of the size and scope of the quality of a great relationship, improve the quality of journal editing is one of the key factors to improve the quality of College journals. This paper analyzes the connotation of college journal editing quality structure and points out that the journal editors should have the 
political quality, academic quality, professional quality, psychological quality and service quality. The quality structure is the important guarantee of high quality of college journals.

\section{References}

[1] Hu Hong, An Analysis of the Quality Structure of College Journal Editors, J. Journal of Sichuan University of Science \& Engineering (Social Sciences Edition). 5(2008) 133 - 136.

[2] Ruth Freitag, Structure of Sci-Tech Periodical Editors' Psychological Quality and Its Optimization, J. Journal of Mingjiang University. 4(2008) 99 - 102.

[3] $\mathrm{Xu}$ Wenjie, On Journal Editors' Knowledge Structure, J. Journal of Dalian Education University. 4(2013) $79-80$.

[4] Sheng Yulan, Discussion on qualities of the editors in colleges and universities, J. Journal of Changsha Telecommunications and Technology Vocational College. 4(2009) 19 - 21. 